\title{
O "ESTADO DA ARTE" DA RECLAMAÇÃO NO STF E NO STJ: O GATO DE SCHRÖDINGER ESTÁ VIVO-MORTO? ${ }^{1}$
}

\section{THE “STATE OF THE ART” OF THE CLAIM IN THE STF AND STJ: IS SCHRÖDINGER'S CAT ALIVE-DEAD?}

Júlio César Rossi

Pós Doutor pela Universidade de Coimbra (UC/PT) com estágio pós doutoral na Universidade do Vale do Rio dos Sinos (UNISINOS). Doutor pela Pontifícia Universidade Católica de São Paulo (PUC/SP). Membro da Associação Brasileira de Direito Processual (ABDPro). Advogado da União (AGU). Brasília/DF. E-mail:julio_rossi@uol.com.br.

\section{Luís Gustavo Reis Mundim}

Mestre e especialista em Direito Processual pela Pontifícia Universidade Católica de Minas Gerais - PUC/MINAS. Pósgraduando em Gestão de Negócios pela Fundação Dom Cabral. Advogado e professor universitário. Membro da ABDPRO - Associação Brasileira de Direito Processual, ACADEPRO - Academia de Direito Processual e INPEJ Instituto Popperiano de Estudos Jurídicos. Belo Horizonte/MG. E-mail: luis.mundim@ reismundim.adv.br.

RESUMO: O presente artigo objetiva analisar o estado da arte da Reclamação Constitucional no Supremo Tribunal Federal e no Superior Tribunal de Justiça, eis que cada tribunal possui um entendimento acerca do cabimento de tal instituto. Nesse sentido, verificou-se que a perspectiva do Superior Tribunal de Justiça, por não entender pelo cabimento da Reclamação para rediscussão de provimentos vinculantes, acaba por cristalizar o direito e implementar uma falsa segurança jurídica, além de impedir a fiscalidade de suas

\footnotetext{
${ }^{1}$ Artigo recebido em 17/05/2021 e aprovado em 18/06/2021.
} 
decisões. O procedimento metodológico utilizado foi o jurídico-teórico, já que se analisou criticamente os entendimentos de tais tribunais a partir de uma perspectiva da processualidade democrática. Foi possível demonstrar que, o estado da arte da Reclamação Constitucional no Brasil, encontra-se como o gato de Schrödinger: vivo-morto.

PALAVRAS-CHAVE: Reclamação Constitucional. Precedentes. Supremo Tribunal Federal. Superior Tribunal de Justiça. Processo democrático.

ABSTRACT: This article aims to analyze the state of the art of the Constitutional Claim in the Supreme Federal Court and in the Superior Court of Justice, since each court has an understanding about the appropriateness of such an institute. In this sense, it was found that the perspective of the Superior Court of Justice, as it does not understand the Complaint's suitability for rediscussing binding provisions, ends up crystallizing the law and implementing a false legal certainty, in addition to preventing the taxation of its decisions. The methodological procedure used was the legal-theoretical one, since the understandings of such courts were critically analyzed from a perspective of democratic procedurality. It was possible to demonstrate that the state of the art of the Constitutional Complaint in Brazil, is like Schrödinger's cat: alive-dead.

KEYWORDS: Constitutional complaint. Precedents. Federal Court of Justice. Superior Justice Tribunal. Democratic process.

\section{I - INTRODUÇÃO}

O instituto da Reclamação Constitucional ganhou novos contornos a partir da promulgação do Código de Processo Civil de 2015, o qual tratou de diversas hipóteses de cabimento, além da previsão constitucional desde 1988. O CPC também vinculou a Reclamação ao que muitos têm denominado de sistema de precedentes.

Nesse sentido, o problema a ser analisado no presente trabalho é o estado da arte da Reclamação no Supremo Tribunal Federal e no Superior Tribunal de Justiça, em especial deste último, que no julgamento da Rcl 36.476 entendeu pelo não cabimento da Reclamação para discussão de pronunciamentos vinculantes. 
Assim, na primeira parte do trabalho analisar-se-á, de modo sucinto, qual o enquadramento normativo da Reclamação no direito brasileiro e suas hipóteses de cabimento relativas aos provimentos vinculantes, tanto na perspectiva constitucional quanto da lei procedimental, em que se defenderá a Reclamação como ação constitucional.

Na segunda parte serão estudados os entendimentos do Supremo Tribunal Federal e do Superior Tribunal de Justiça acerca do cabimento da reclamação, os quais são antagônicos e distintos acerca do cabimento de tal instituto, o que gera conflito de entendimentos, além de divergência e imprevisibilidade decisórias sobre a temática.

$\mathrm{Na}$ terceira parte, demonstrar-se-á que o entendimento do Superior Tribunal de Justiça impossibilita que o próprio tribunal reveja seus entendimentos fixados, eis que, por entender pelo não cabimento da Reclamação Constitucional, não existem outros meios para a revisitação dos precedentes o que vai de encontro à processualidade democrática e à legitimidade decisória.

Por fim, concluiu-se que o "estado da arte" da Reclamação se assemelha ao destino do Gato de Schrödinger, em que não se sabe se dentro da caixa está vivo ou morto, já que STF e STJ possuem entendimentos distintos sobre o tema.

Assim, não houve a pretensão de se esgotar a temática, porém, espera-se que se tenha realizado uma contribuição crítica e reflexiva.

\section{II - DO ENQUADRAMENTO NORMATIVO DA RECLAMAÇÃO E DAS HIPÓTESES DE CABIMENTO RELATIVAS AOS PROVIMENTOS VINCULANTES}

A reclamação é garantia constitucional processual estabelecida no art. 102, I, alínea “l”, bem como no art. 105, I, alínea "f” da Constituição Federal. Ambos os dispositivos estabelecem o instituto para, em relação ao Supremo Tribunal Federal e ao Superior Tribunal de Justiça (i) preservar-lhes as respectivas competências jurisdicionais e (ii) garantir-lhes a autoridade de suas decisões.

Discutiu-se consideravelmente acerca de qual o tipo de garantia pertencente à sistemática dos meios processuais de impugnação cuidar-se-ia a reclamação, pois, a depender do enquadramento a lhe ser conferido, a definição quanto ao procedimento, a 
Revista Eletrônica de Direito Processual - REDP.

Rio de Janeiro. Ano 15. Volume 22. Número 3. Setembro a Dezembro de 2021

Periódico Quadrimestral da Pós-Graduação Stricto Sensu em Direito Processual da UERJ

Patrono: José Carlos Barbosa Moreira (in mem.). ISSN 1982-7636. pp. 523-540

www.redp.uerj.br

espécie de decisão e a competência do órgão jurisdicional para dela conhecer, processar e julgar ganham relevo.

Desde sua origem no sistema brasileiro, inicialmente fruto de construção jurisprudencial do STF calcada na teoria dos poderes implícitos (implied and inherent powers theory), até a chegada do Código de Processo Civil de $2015^{2}$, diversas naturezas jurídicas lhe foram imputadas, tais como: (i) recurso $^{3}$, (ii) incidente processual ${ }^{4} \mathrm{e}$ (iii) direito de petição ${ }^{5}$.

Parece-nos, entretanto, mais acertada a natureza jurídica de ação ${ }^{6}$, notadamente a partir do advento do CPC (arts. 988 usque 993), ao estabelecer que a reclamação: (i) pressupõe iniciativa da parte para o manejo; (ii) objetiva a correta aplicação do direito, impedindo afronta a decisões vinculantes ou usurpação da competência dos Tribunais; (iii) instaura lide; (iv) cria procedimento próprio e; por fim, (v) sua decisão perfaz coisa julgada.

\footnotetext{
2 Para uma análise a respeito da origem e evolução da reclamação no sistema constitucional processual brasileiro, consultar: ASSIS, Araken de. Manual dos recursos. 8. ed., São Paulo: RT, 2016, p. 1.057-1.059.

3 "A reclamação tem semelhanças com os recursos, pois é utilizada para questionar perante tribunal superior decisão que aplicou o direito de maneira considerada errônea. Contudo, não se confunde com os recursos, pois um dos mais importantes requisitos para recorrer é a sucumbência (perda da ação). Só recorre quem perdeu. Já no caso da reclamação constitucional, reclama quem ganhou, exigindo que se aplique decisão anterior que beneficia o recorrer. Esse argumento convence na substância, mas não formalmente, pois na reclamação protesta a parte que foi prejudicada por certa decisão, invocando decisão anterior que o favoreceu. $\mathrm{O}$ fato é que o efeito vinculante da decisão anterior deveria impedir a decisão discrepante e a reclamação constitucional pode ser usada contra decisão administrativa e não somente judicial, ao contrário do recurso. Por fim, os recursos têm rígidos prazos preclusivos, enquanto a reclamação não tem prazo determinado. Logo a reclamação não pode ser considerada recurso" DIMOULIS, Dimitri; LUNARDI, Soraya. Curso de processo constitucional: controle de constitucionalidade e remédios constitucionais. 7. ed. São Paulo: RT, 2020, p. 334335.

4 "A reclamação foi considerada incidente processual, aproximando-se do procedimento de conflito de competência. Isso não convence, pois reclamação não se limita preservar competência de certo tribunal. Constitui também meio de imposição da interpretação adotada pelo STF, sendo justamente essa a finalidade da reclamação constitucional que examinamos aqui. A alegação de que se está impugnando decisão tomada em outro processo, surgindo um incidente, não é adequada. Primeiro, porque não se exclui, em tese, a reclamação após o trânsito em julgado de uma decisão, ao contrário do incidente. Segundo - e mais importante -, porque a ligação processual entre duas demandas não indica sempre que a segunda seja incidente da primeira. Com efeito, as cautelares e as rescisórias são ações autônomas e não incidentais apesar da clara ligação processual com a ação principal” DIMOULIS; LUNARDI, Op. cit., p. 335.

5 "Seguindo parte da doutrina, o STF decidiu que a reclamação 'situa-se no âmbito do direito constitucional de petição, previsto no art. $5^{\circ}$, XXXIV, da Constituição Federal'. Esse entendimento possibilita que a regulamentação do instituto ocorra em âmbito estadual, por ser questão de procedimento, não havendo invasão de competência privativa da União para legislar sobre direito processual (art. 22, I e 24, XI, da CF)". DIMOULIS; LUNARDI, Op. cit., p. 335. Todavia, cabe esclarecer que na Rcl 1.728, Rel. Min. Luiz Fux, jul. 24.11.2015, Dje 18.4.2016, a Primeira Turma do STF reconheceu a natureza de ação à reclamação.

${ }^{6}$ ROSSI, Júlio César. Aspectos processuais da reclamação constitucional. Revista Dialética de Direito Processual, n. 19, p. 49-60, out. 2004; ABBOUD, Georges. Processo constitucional brasileiro. 3. ed. São Paulo: RT, 2019, p. 907-908; MEDINA, José Miguel Garcia. Curso de direito processual civil moderno. 3. ed. São Paulo: RT, 2017, p. 1.375; DIMOULIS; LUNARDI, Op. cit., p. 335-336 e ASSIS, Op. cit., p. 1.060.
} 
No mesmo sentido, Fernanda Gomes Borges e Souza entende que "a reclamação constitucional é ação constitucional diante do papel que exerce, bem como das consequências processuais que origina"7.

Assim, o instituto pode ser conceituado como sendo ação cujas finalidades são: (i) assegurar a competência do STF e do $\mathrm{STJ}^{8}$ nas hipóteses em que quaisquer decisões ou atos emanados pelos órgãos da função Jurisdicional e da Administração Pública direta e indireta nas esferas federal, estadual ou municipal venham a afrontá-la; (ii) garantir a autoridade das decisões vinculantes proferidas pelo STF/STJ e; por fim, (iii) garantir a observância de acórdão de recurso extraordinário com repercussão geral reconhecida e julgada ou de aresto proferido em julgamento de recursos extraordinário ou especial repetitivos, percorridas as instâncias ordinárias.

Embora, como asseverado, a reclamação constitua ação que atende a diversas finalidades (CPC, art. 988), interessa-nos abordar, especificamente, as hipóteses que dizem respeito à garantia da observância de decisões vinculantes nos moldes gizados no art. 988, III e $\S 5^{\circ}$, II do CPC.

Proferido o julgamento pelo STF e fixada a tese vinculante, havendo decisões judiciais ou administrativas que as violem, fica franqueado às partes legitimadas e ao Ministério Público o ajuizamento da reclamação: (i) diretamente no Tribunal, cuidando-se de transgressão a (i.1.) enunciados de súmulas vinculantes e (i.2.) decisões proferidas em controle concentrado de constitucionalidade ${ }^{9}$ e; (ii) desde que (ii.1.) antes do trânsito em julgado da decisão reclamada e (ii.2.) esgotadas as instâncias ordinárias, na hipótese de a decisão judicial desatender ao comando vinculante firmado em (iii.1.) recurso extraordinário com repercussão geral reconhecida e julgada e (iii.2.) recurso extraordinário repetitivo.

No âmbito do STJ, em contrapartida, a via da reclamação será oportunizada aos legitimados presentes as condicionantes (ii.1.) e (ii.2.), quando o objeto impugnado (=decisão judicial ou administrativa) estiver afrontando o parâmetro normativo consolidado

\footnotetext{
7 BORGES, Fernanda Gomes e Souza. Os novos contornos da reclamação constitucional no Código de Processo Civil de 2015. Revista Brasileira de Direito Processual - RBDPro, Belo Horizonte, ano 26, n. 102, p. 235-256, abr./jun. 2018, p. 247.

${ }^{8}$ Adverte-se que, neste ensaio, o instituto será abordado no ambiente relativo às competências do STF e do STJ.

${ }^{9}$ Destaca-se, por oportuno, que possuem efeitos vinculantes não só a decisão final de mérito (acórdão) como também a eventual medida liminar cautelar eventualmente concedida, nos termos dos arts. $11, \S 1^{\circ}$ e 28 , parágrafo único, da Lei 9.868/99.
} 
em sede de recurso especial repetitivo.

Em relação ao significado de "esgotamento das instâncias ordinárias", o art. 988, $\S 5^{\circ}$, II do CPC é expresso em não admitir o manejo da reclamação para garantir a observância de decisões firmadas em RE-RG, RE repetitivo e REsp repetitivo antes do esgotamento das "vias normais", entendida estas como sendo não só “a interposição dos recursos vocacionados à obtenção de decisão final no tribunal local" ${ }^{\prime 10}$ (CPC, art. 1.021 c.c. art. $1.030, \S 2^{\circ}$ ), mas igualmente "após a manifestação da presidência ou vice-presidência dos tribunais no momento da realização do juízo de admissibilidade de REsp e RE, não realizando juízo de retratação" ${ }^{11}$. Adota-se, portanto, em regra, o caráter subsidiário da reclamação ${ }^{12}$.

Nessa esteira, infere-se que a Reclamação, como instituto processual, pode ser enquadrada normativamente como ação e possui hipóteses claras de cabimento, principalmente em relação aos pronunciamentos vinculantes. Contudo, STF e STJ têm divergido acerca das hipóteses de cabimento, o que, via de consequência, acaba por vilipendiar a processualidade democrática ${ }^{13}$ e o devido processo legal.

\section{III - DOS ENTENDIMENTOS DO SUPREMO TRIBUNAL FEDERAL E DO SUPERIOR TRIBUNAL DE JUSTIÇA ACERCA DO CABIMENTO DA RECLAMAÇÃO}

No que diz respeito à compreensão do "parâmetro da reclamação", STF e STJ possuem entendimentos colidentes e ambíguos. Vejamos.

Sabe-se que o parâmetro da reclamação deveria ser o conjunto de normas em nível constitucional - denominado bloco de constitucionalidade. Todavia, do ponto de vista estritamente processual, sabe-se que a discussão se reduz à ideia de confirmar se a

\footnotetext{
${ }^{10}$ MEDINA, Op. cit., p. 1.377.

${ }^{11}$ ABBOUD, Op. cit., p. 914-915. Nesse sentido: Rcl 32.945/RS, Min. Relator Reynaldo Soares da Fonseca,

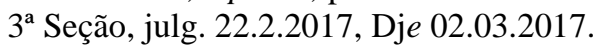

12 Deve-se registrar, todavia, como hipóteses de exceções à subsidiariedade, a Rcl 6318, Rel. Min. Teori Zavascki, julg. 29.9.2009 e nas medidas liminares na Rcl 32.035, Rel. Min. Ricardo Lewandowski, jul. 28.9.2018 e 01.10.2018, nas quais o STF reconheceu o cabimento de reclamação antes do esgotamento dos recursos do processo principal, inclusive, algumas que suspenderam ação penal antes da primeira audiência, cf. DIMOULIS; LUNARDI, Op. cit., p. 339, nota $\mathrm{n}^{\circ} .81$.

${ }^{13}$ GRESTA, Roberta Maia. Introdução aos fundamentos da processualidade democrática. Coleção estudos da Escola Mineira de Processo. Rio de Janeiro: Lumen Juris, 2014. v. 01.
} 
Rio de Janeiro. Ano 15. Volume 22. Número 3. Setembro a Dezembro de 2021

Periódico Quadrimestral da Pós-Graduação Stricto Sensu em Direito Processual da UERJ

Patrono: José Carlos Barbosa Moreira (in mem.). ISSN 1982-7636. pp. 523-540

www.redp.uerj.br

interpretação fixada e aplicada pelo STF foi respeitada pelas demais instâncias do Judiciário e demais entidades da Administração.

Com efeito, muito embora o art. 998, III e $\S 5^{\circ}$, II, pareça deixar claro que a vinculação aos precedentes compreende tanto as suas razões de decidir quanto o seu dispositivo (por força do efeito vinculante e erga omnes a eles estabelecidos por lei), permitindo que qualquer interessado ou MP possam manejar a reclamação quando o objeto (=ato reclamado) violar o parâmetro firmado pelo STF, a jurisprudência do Tribunal oscila ${ }^{14}$, criando um ambiente de arrepsia jurídica.

O CPC, ao autorizar o aforamento da reclamação pelos legitimados (=partes interessadas ou MP) com o desígnio de garantir a observância do parâmetro consolidado tanto em controle abstrato (CPC, art. 998, III) quanto em controle difuso (CPC, art. 988, §5 II), acolhe, logicamente, que todo e qualquer interessado, parte ou não no processo piloto/modelo/padrão no bojo do qual restou formado o paradigma tenha legitimidade para, fazendo uso da ação, oportunize ao STF/STJ conhecê-la, adequando o ato impugnado ao pronunciamento vinculante ou revendo-o/superando-o ${ }^{15}$, sob pena de torná-la inócua, inútil e despicienda.

Desse modo, especificamente, em relação ao STF, não faz sentido que o mesmo

\footnotetext{
${ }^{14}$ Adotando a teoria da transcendência: Reclamação 2.363, Rel. Min. Gilmar Mendes, jul. 23.10.2003; Medida Cautelar na Reclamação 2.986, Real. Min. Celso de Mello, julg. 11.3.2005; Reclamação 4.987, Rel. Min. Gilmar Mendes, julg. 07.3.2007. Não a adotando: Agravo Regimental na Reclamação 5.082, Rel. Min. Ellen Gracie, julg. 19.4.2007; Agravo Regimental na Reclamação 2.475, Rel. Min. Carlos Velloso, julg. 02.8.2007; Agravo Regimental na Reclamação 2.990, Rel. Min. Sepúlveda Pertence, julg. 16.8.2007.

15 "Para efeitos didáticos, vale distinguir revisão de superação. De acordo com o art. 986 do CPC, inserido no capítulo que dispõe o Incidente de Resolução de Demanda Repetitivas, a revisão da tese jurídica tem lugar no mesmo tribunal que a instituiu, sendo que pode ser por ele próprio realizada de ofício, ou requerimento pelo Ministério Público ou pela Defensoria Pública, por petição. O disposto vale também para os casos de julgamento dos recursos extraordinário e especial repetitivos, cujas revisões serão feitas no STF ou no STJ, respectivamente. Revisar a tese jurídica firmada significa reinterpretá-la de modo a ressignificar seu contexto de incidência, seja para ampliá-lo, reduzi-lo o mesmo para anulá-lo. De outro ângulo, a superação do entendimento sediado nos provimentos vinculante não se sujeita a uma 'análise concentrada', isso porque, no caso concreto, é plenamente possível que o juiz competente afaste a incidência do provimento em razão de vislumbrar novo argumento, participado pelas partes (arts. $9^{\circ}$ e 10 do CPC), estranho aos fundamentos que embasaram aquele teto vinculante. Isso ocorrendo, não haverá qualquer óbice para que o juiz conheça da 'nova fundamentação`e, uma vez procedente, decida a causa admitindo-a. (...) Notem que tal possibilidade decorre diretamente da exigência constitucional da motivação das decisões judiciais (art. 93, IX, da CF), a qual estabelece que as decisões devem ser adequadamente fundamentadas (art. 489, $\S 1^{\circ}$ e incisos do CPC). O próprio inciso VI desse artigo legal afirma que não pode o juiz deixar de seguir enunciado de súmula, jurisprudência ou precedente, sem que demonstre a superação do entendimento firmado nesses textos vinculantes. (...) A diferenciação ora apresentada é imprescindível para permitir que não haja engessamento jurisprudencial brasileiro e que possibilite a ressignificação de teses e institutos jurídicos em razão da historicidade". ABBOUD, Op. cit., p. 1.117-1.119.
} 
Tribunal diante da legislação em vigor produza decisões que, por um lado, aceitam a reclamação como meio processual hábil a revisar parâmetros vinculantes forjados em controle difuso - como o fez o Min. Roberto Barroso na Rcl 30.210 (DJe 08.5.2018), ao propiciar a "revisão de tese, a fim de não engessar a jurisprudência à vista de novas necessidades ou de uma mudança de perspectiva com o passar do tempo" e o Min. Edson Fachin na Rcl 21.409 (DJe 25.4.2016), ao consignar que "por diversas vezes, o Supremo Tribunal Federal, ao julgar reclamações, redefiniu o alcance e o sentido de suas próprias decisões apontadas como parâmetros da reclamação (...) porquanto a abertura hermenêutica da jurisdição constitucional exige a utilização da reclamação com todas suas potencialidades instrumentais" - e, por outro, também no ambiente do controle concreto, negam-na, ao fundamento de que o instituto não se presta a "garantir a autoridade de decisão proferida em processo de índole subjetiva, do qual não tenha participado o reclamante", como consignou a Min. Rosa Weber na Rcl 40.257 (DJe 05/05/2020).

No STJ, recentemente, a garantia constitucional processual estabelecida no art. 105, I, alínea "f”, da CF e procedimentalizada no art. 988 do CPC recebeu um duro baque.

Considerando o arquétipo estabelecido pela lei processual para formação, controle e superação de pronunciamentos vinculantes, o Tribunal Superior, a partir do julgamento, por maioria, da Rcl 36.476 (Corte Especial, julg. 05.02.2020, DJe 06.03.2020) ${ }^{16}$, resolveu pelo não cabimento da ação na hipótese de os legitimados, face a um pronunciamento destoante entre a solução conferida ao caso concreto e o paradigma normativo obrigatório, pretenderem a revisitação da tese firmada sobre a matéria.

Portanto, doravante, aos legitimados foi suprimido o uso da reclamação como meio processual adequado a provocar o STJ à reconstrução de conteúdos vinculantes dele originados.

Em síntese, os fundamentos contidos na Rcl 36.476 foram que: (i) “não há coerência e lógica em se afirmar que o parágrafo $5^{\circ}$, II, do art. 988 do CPC, com a redação dada pela Lei 13.256/2016, veicularia uma nova hipótese de cabimento da reclamação", pois, segundo

16 "RECLAMAÇÃO. RECURSO ESPECIAL AO QUAL O TRIBUNAL DE ORIGEM NEGOU SEGUIMENTO, COM FUNDAMENTO NA CONFORMIDADE ENTRE O ACÓRDÃO RECORRIDO E A ORIENTAÇÃO FIRMADA PELO STJ EM RECURSO ESPECIAL REPETITIVO (RESP 1.301.989/RS TEMA 658). INTERPOSIÇÃO DE AGRAVO INTERNO NO TRIBUNAL LOCAL. DESPROVIMENTO. RECLAMAÇÃO QUE SUSTENTA A INDEVIDA APLICAÇÃO DA TESE, POR SE TRATAR DE HIPÓTESE FÁTICA DISTINTA. DESCABIMENTO. PETIÇÃO INICIAL. INDEFERIMENTO. EXTINÇÃO DO PROCESSO SEM RESOLUÇÃO DO MÉRITO”. 
a Corte Especial "o parágrafo se inicia, ele próprio, anunciando que trataria de situações de inadmissibilidade da reclamação"; (ii) "a investigação do contexto jurídico-político em que editada a Lei 13.256/2016 revela que, dentre outras questões, a norma efetivamente visou ao fim da reclamação dirigida ao STJ e ao STF para o controle da aplicação dos acórdãos sobre questões repetitivas, tratando-se de opção de política judiciária para desafogar os trabalhos nas Cortes de superposição"; (iii) "a admissão da reclamação na hipótese em comento atenta contra a finalidade da instituição do regime dos recursos especiais repetitivos, que surgiu como mecanismo de racionalização da prestação jurisdicional do STJ, perante o fenômeno social da massificação dos litígios"; (iv) no regime de provimentos vinculantes, máxime os relativos aos REsp repetitivos "o STJ se desincumbe de seu múnus constitucional definindo, por uma vez, mediante julgamento por amostragem, a interpretação da Lei federal que deve ser obrigatoriamente observada pelas instâncias ordinárias", sendo que "uma vez uniformizado o direito, é dos juízes e Tribunais locais a incumbência de aplicação individualizada da tese jurídica em cada caso concreto" e; por fim, (v) "em tal sistemática, a aplicação em concreto do precedente não está imune à revisão, que se dá na via recursal ordinária, até eventualmente culminar no julgamento, no âmbito do Tribunal local, do agravo interno de que trata o art. 1.030, $\S 2^{\circ}$, do CPC/15".

Não obstante a possibilidade de as partes provocarem o Tribunal local para realização da distinção entre o mérito do seu recurso e o do paradigma vinculante extraído do REsp repetitivo, aliás, como é possível à luz dos arts. 10,489, § $1^{\circ}$, VI e $927, \S 1^{\circ}$, do CPC, o fato é que, entre os cinco possíveis fundamentos que pudemos extrair da decisão, todos eles negam vigência ao art. 105, I, alínea "f” da CF c.c. o art. 988, §5, II, do CPC, ao tolher dos legitimados o manuseio autônomo da reclamação tal qual previsto no ordenamento jurídico positivo.

Com efeito, sem embargo de clara supressão judicial (=uma espécie de reconhecimento de inconstitucionalidade despida da exigência fulcrada no art. 97 da CF) na utilização da garantia constitucional processual por parte dos legitimados, o que se nota do conteúdo da decisão da Corte Especial do STJ são extensas digressões político-jurídicas a respeito da melhor colmatação do instituto, notadamente, em relação ao seu cabimento para revisar ou superar provimentos vinculantes (CPC, art. 988, §5º, II).

Destarte, levando em sérias considerações: 
os propósitos para os quais um sistema normativo como o direito é criado (um sistema institucionalizado, planejador, pretensamente autoritativo) e o ambiente em que os brasileiros hoje vivem (...), é desejável que magistrados deem sequência ao planejamento jurídico-social, de modo a seguir aquilo que pode ser extraído do ponto de vista jurídico, mesmo que esse ponto de vista jurídico viole suas concepções sobre justiça ${ }^{17}$.

Ora, a decisão política foi tomada em seu habitat constitucional e adequadamente positivada no CPC de 2015, restando-nos promover a interpretação do texto normativo. A arena propícia para rediscussão do acerto ou equívoco da opção política não é o Judiciário (=in casu, o STJ), mas o Parlamento Nacional. Enquanto isso não for objeto de retomada por meio das competentes iniciativas legislativas (=projeto de lei), conformamo-nos com a missão do Judiciário: a interpretação da norma positivada no ordenamento jurídico em vigor.

Dito de outro modo: a cizânia anterior à lei não pertence ao domínio jurídico e, portanto, contemptível rediscuti-la na decisão judicial. O imperativo da autocontenção inerente a atuação do Judiciário no exercício de suas competências corresponde à necessidade de se respeitar o espaço político que foi concedido ao legislador ao regrar as hipóteses de cabimento da reclamação no horizonte do CPC em conformidade com a Constituição. Ao Judiciário é vedado, recorrendo a artificiais sopesamentos ou ponderações decidir de forma contrária ao texto legislado, salvo quando isso fundamentar-se diretamente no Texto Constitucional, o que, data venia, não nos parece nem de longe a hipótese.

A perpetuar-se o entendimento firmado na Rcl 36.476, o STJ retirará de forma oblíqua do ordenamento a ação direta para cassação judicial (CPC, art. 992) de provimentos dotados de eficácia vinculante. Vedado o uso da reclamação contra decisões de instâncias inferiores que tenham contrariado diretamente REsp repetitivo, a única via de acesso ao Tribunal Superior para a correção da desconformidade será dirigir um novo recurso especial. 18

Evidentemente que a utilização dos recursos, em termos gerais, parece-nos, em um sistema jurídico que não disponha de engenhos mais adequados e eficazes, de fato, a melhor das soluções.

Porém, tendo-se em mira o CPC atual, a interposição de novo REsp contra o acórdão

\footnotetext{
17 TORRANO, Bruno. Pragmatismo no direito e a urgência de um pós-pós-positivismo no brasil. Rio de Janeiro: Lumen juris, 2018, p. 211.

${ }^{18}$ Sobre o cabimento de novo REsp, consultar: NUNES, Dierle; FREITAS, Marina Carvalho. O STJ e a necessidade de meios para a superação dos precedentes. Consultor jurídico. São Paulo, 22 nov. 2017. Disponível em: https://bit.ly/3jDBp29.
} 
proferido pelo órgão especial do Tribunal local - que, analisando recurso de agravo interposto contra a decisão do Presidente ou Vice-Presidente, mantém o posicionamento em desacerto com o parâmetro vinculante estabelecido pelo STJ em regime de REsp repetitivo para a mesma hipótese fático-jurídica - parece-nos ineficiente, pois, como cediço, a admissibilidade do recuso excepcional revela-se na práxis extremamente restrita, podendo ser negado o seu juízo de prelibação por conta dos mais diversos aspectos (=intrínsecos/extrínsecos).

Logo, o que se poderá perceber é que o entendimento do Superior Tribunal de Justiça não passa de um réquiem à processualidade democrática e à legitimidade decisória, já que impede o acesso ao referido tribunal para revisitação dos entendimentos firmados em sede de recursos repetitivos.

\section{IV - DA IMPOSSIBILIDADE DE REVISITAÇÃO DOS PRONUNCIAMENTOS VINCULANTES: O RÉQUIEM DA PROCESSUALIDADE DEMOCRÁTICA E DA LEGITIMIDADE DECISÓRIA}

Nota-se que, o STF e o STJ não cristalizaram um entendimento seguro sobre o significado processual dos elementos (=parâmetro e objeto) que compõem relevante espectro do instituto da reclamação mesmo diante de uma dicção que, salvo melhor juízo, parece-nos clara: as decisões produzidas sob o signo de vinculantes (=efeito) e erga omnes (=eficácia) constantes do art. 927 do CPC, no caso de descumprimento ou inobservância pelos outros órgãos do Poder Judiciário e diversas esferas da Administração Pública, franquiam aos legitimados - sem prejuízo da impetração de ação mandamental ${ }^{19}$ e dos recursos

\footnotetext{
${ }^{19}$ Recentemente (26/05/2021) a Primeira Turma do STJ fixou o entendimento segundo o qual revela-se cabível a impetração de mandado de segurança contra decisão do Tribunal local que deixa de aplicar ou aplica equivocadamente tese firmada em recurso especial repetitivo. Tal compreensão lastreia-se nessa ideia baralhada do não cabimento da reclamação como meio adequado de revisão e superação de provimentos vinculantes. Assim, ao menos para aquele órgão fracionário do STJ, a "irrecorribilidade do acórdão objeto da impetração, que nem sequer admite reclamação", evidencia "situação de exceção a admitir a via do mandamus" (STJ, Primeira Turma, AgInt no RMS 53.790/RJ, Min. Relator Gurgel de Faria, DJ 17/05/2021, DJe 26/05/2021). Mais uma vez foi negado vigência ao instituto da reclamação, impondo aos Tribunais locais a missão de revisitar provimentos dotados de eficácia vinculante, missão essa atribuída ao STJ e ao STF. A referida decisão para além de inadequada e ilegal, traz em seu bojo diversas questões de alta indagação, $p$. ex.: qual o prazo para a impetração? O que vem a ser "decisão teratológica" para fins de aplicação de teses vinculantes? O mandado de segurança tornou-se sucedâneo recursal ad hoc? Contra o indeferimento liminar ou negada a segurança, o STJ faria o controle de seus julgados vinculantes através de recurso em mandado de segurança (RMS)? Em caso de concessão de medida liminar, o STJ conheceria e processaria eventual pedido
} 
eventualmente cabíveis à espécie ${ }^{20}$, bem assim preenchidos os requisitos procedimentais estabelecidos no art. $988, \S 5^{\circ}, \mathrm{I}^{21}$ e II do CPC - a via direta de acesso àqueles Tribunais .

Destaca-se, por oportuno, que não se está defendendo a utilização da reclamação como "atalho", expediente "per saltum", ou mesmo "sucedâneo recursal", mas impingindo sua força normativa estabelecida na CF e no CPC, de tal maneira que esse último diploma estabelece como conditio sine quo non (i) a inexistência de trânsito em julgado do objeto reclamado e (ii) o esgotamento das instâncias ordinárias, para ajuizamento da reclamação tanto pelas partes diretamente atingidas pela decisão negatória do paradigma repetitivo, quanto por qualquer um que possa ser atingido pelo provimento vinculante dada a ampla legitimidade peculiar desta ação.

De tal modo, conquanto se reconheça que a partir do julgamento do agravo (CPC, art. 1.021) pelo Tribunal local, sejam cabíveis embargos de declaração (CPC, art. 1.022), agravo (CPC, art. 1.042) ${ }^{22}$, sem prejuízo da interposição de novos recursos especial ou extraordinário (por ofensa aos art. 102, caput e III e 105, III c.c. CPC, art. 489, §1º, VI, do CPC) ou mesmo ação rescisória pautada no CPC, art. $966, \mathrm{~V}, \S \S 5^{\circ}$ e $6^{\circ}$ - todos aparentemente

\footnotetext{
de suspensão? Essas são alguns efeitos colaterais da decisão tomada na decisão aqui criticada e que merece um estudo à parte.

20 “Art. 988. Caberá reclamação da parte interessada ou do Ministério Público para: (...) $\S 6^{\circ} \mathrm{A}$ inadmissibilidade ou o julgamento do recurso interposto contra a decisão proferida pelo órgão reclamado não prejudica a reclamação (g.n.)". Por evidente que, não sendo a reclamação uma espécie de recurso, aforada a ação diretamente no STF/STJ, a inadmissão do recurso ou o seu julgamento em nada afetará o instituto, quer em razão da distinção de órgãos para julgar tanto um quanto o outro, quer em razão da ampla autonomia procedimental existente entre os dois meios de impugnação.

${ }^{21}$ Em relação a esse requisito negativo, esclareça-se que a legislação $(=\mathrm{CPC})$ incorporou o teor da Súmula 734 do STF: "Não cabe reclamação quando já houver transitado em julgado o ato judicial que se alega tenha desrespeitado decisão do Supremo Tribunal Federal" (aprovada em Sessão Plenária de 26.11.2003).

${ }^{22}$ A respeito do cabimento do recurso de agravo previsto no art. 1.042 do CPC, acertada se mostra a conclusão de Nelson Nery Júnior e Georges Abboud: "O cabimento do agravo do CPC 1042 contra a decisão colegiada do TRF ou TJ que, ao julgar o agravo interno, mantém a decisão do Presidente ou Vice-Presidente do tribunal que negou seguimento ao RE/REsp (CPC 1030 I) ou julgou a questão do sobrestamento (CPC 1030 III), é conclusão que se extrai do sistema constitucional, para que se dê ao CPC 1030 § 2. ${ }^{\circ}$ e CPC 1042 conformidade constitucional, que fixa a competência do STF e do STJ para julgar o RE e o REsp, respectivamente. Isto significa que a sistemática trazida pela reforma constante da Lei 13.256/2016 só não será inconstitucional se se der aos dispositivos aqui mencionados interpretação conforme a Constituição. Criou-se, na verdade, mais uma etapa para o juízo de admissibilidade de RE/REsp: negado seguimento ao recurso ou julgada a questão do sobrestamento, o recorrente não poderá interpor agravo diretamente no STF/STJ, mas sim deverá interpor agravo interno (CPC 1021) para o colegiado do tribunal local. Este é o passo intermediário criado pela Lei 13.256/2016. O entendimento contrário, de que não caberia nenhum recurso do acórdão que resolver o agravo interno, ensejaria a conclusão de que estaria sendo subtraída a competência constitucional do STF/STJ, ou, caso os tribunais superiores concordem com esse sistema, estariam renunciado à competência constitucional imposta a eles por texto expresso, o que é inadmissível" ABBOUD, Georges; NERY, Nelson. Recursos para os tribunais superiores e a lei 13.256/2016. Revista de Processo n. 257. São Paulo: RT, jul. 2016, p. 233-234.
} 
ineficazes diante da reclamação -, STF e STJ expungiram essa típica garantia constitucional processual como sendo a via adequada para que os legitimados possam requerer a revisitação de provimentos vinculantes, negando-a, ao arrepio do mesmo diploma que os permitiu realizar o "controle de verticalização e de aplicação dos precedentes obrigatórios"23.

Efetivamente, se há uma perspectiva de construção de um sistema de precedentes, a revisitação dos pronunciamentos vinculantes é fundamental para a subsistência do sistema jurídico como um todo. Nessa esteira, é crucial que o tribunal superior responsável pela criação do pronunciamento vinculante possa afastá-lo de ser aplicado à uma lide e, principalmente, de revistá-lo, por meio de distinguishing (distinção) ou overruling (superação) $^{24}$. Ou seja, quando não houver argumentos fático-jurídicos que façam aquele precedente se manter no sistema jurídico, ele deve ser revisitado, sob pena de imunização e engessamento ad aeternum dos julgados.

Nesse sentido, defendemos que a imunização e impossibilidade de revisitação de um precedente é geradora de uma violência normativa:

Outra problemática é defender o pouco uso ou quase nenhum da técnica da superação, sob a justificativa de violação à segurança jurídica. Há a institucionalização de uma rigidez ao sistema de precedentes, ocasionandose uma cristalização do direito, o que acaba por vedar que novos argumentos sejam apresentados ou que argumentos não apreciados quando da formação do precedente apontem aporias que ensejam uma nova formatação ao precedente.

Essa imunização dos entendimentos firmados pelos tribunais sobre o pretexto de segurança jurídica é o que dissimula a relação direito-violência impostas por uma estatalidade de exceção que sincreticamente funda e conserva a violência normativa [...]. ${ }^{25}$

A crítica também é realizada por Fernanda Gomes e Souza Borges, já que o STJ acaba por criar uma espécie de jurisprudência defensiva e super precedentes que engessam o sistema jurídico:

E, por óbvio, a decisão do STJ ora examinada pretendeu reforçar o filtro recursal implementado pela Lei n. 13.256/2016, por meio de jurisprudência defensiva, a contrario sensu, ainda, do entendimento do STF. Ao constatar a defeituosa técnica legislativa o STJ optou por interpretar norma de maneira mais restritiva ao cidadão, violando o devido processo constitucional, ao engessar o sistema e não permitir que a reclamação cumpra seu papel diante do sistema de precedentes que se impôs a partir

\footnotetext{
${ }^{23}$ ARAÚJO, José Henrique Mouta. A reclamação constitucional e os precedentes vinculantes: o controle da hierarquização interpretativa no âmbito local. Revista de Processo n. 252. São Paulo: RT, fev. 2016, p. 9.

24 Sobre a distinção e superação, conferir: MUNDIM, Luís Gustavo Reis. Precedentes: da vinculação à democratização. Belo Horizonte: D’Plácido, 2018, 122-135.

${ }^{25}$ MUNDIM, Luís Gustavo Reis. Op. cit., 2018, p.135.
} 
Revista Eletrônica de Direito Processual - REDP.

Rio de Janeiro. Ano 15. Volume 22. Número 3. Setembro a Dezembro de 2021

Periódico Quadrimestral da Pós-Graduação Stricto Sensu em Direito Processual da UERJ

Patrono: José Carlos Barbosa Moreira (in mem.). ISSN 1982-7636. pp. 523-540

www.redp.uerj.br

do $\mathrm{CPC} / 2015 .^{26}$

Ora, com esse posicionamento, o STJ acaba por transformar sua função constitucional de tribunal recursal ${ }^{27}$ em uma Corte Suprema ${ }^{28}{ }_{2}^{29}$, criadora de teses gerais e $\operatorname{abstratas}^{30}$, as quais podem suspender a legalidade e a constitucionalidade em prol de seus interesses em reduzir processos e julgamentos a todo custo, sem considerar a necessidade de legitimidade democrática e eficiência qualitativa das decisões. ${ }^{31}$

Ao optar pelo não cabimento da Reclamação, o STJ impede, ainda, o exercício de fiscalidade das decisões, já que não é permitido às partes de revisitar o julgado vinculante

\begin{abstract}
${ }^{26}$ BORGES, Fernanda Gomes e Souza. Demérito ao STJ: a relevância da reclamação diante do fenômeno do "manicômio jurisprudencial". Empório do Direito. São Paulo. 03 jun. 2020. Disponível em: https://bit.ly/3hGh4Ye.

${ }^{27}$ Leciona Rosemiro Pereira Leal: 'Do exposto e em se ressaltando que o Brasil não tem 'Supremas Cortes', mas tribunais recursais, uma vez que nossos STF e STJ não podem, em paradigma de Estado Democrático (Estado não Dogmático), atuar pela judicialização da política na qualidade de guardiães míticos (tutores, mentores) de um sacratíssimo livro constitucional brasileiro, como apregoam os seus próprios ministros em sua excelsa e estranha nomenclatura, o instituto processual do precedente adotado pelo $\$ 2^{\circ}$ do art. 926 do CPC/2015 há de ser dimensionado (semanticamente demarcado) a partir da intrassignificatividade normativa posta pelo caput do art. 926 e seu $\$ 1^{\circ}$ a estabelecer o seguinte e novo roteiro configurativo da formação e uniformização da jurisprudência no Brasil a fim de, reduzindo seus erros e fracassos históricos, torná-la "estável, integra e coerente"'. LEAL, Rosemiro Pereira. A questão dos precedentes e o devido processo. Revista Brasileira de Direito Processual-RBDPro, Belo Horizonte, ano 25, n. 98, p. 295-313, abr./jun.2017, p. 306-307.
\end{abstract}

${ }^{28}$ A tese de que os Tribunais Superiores - STF e STJ - são Cortes Supremas é encampada principalmente por Daniel Mitidiero e Luiz Guilherme Marinoni: MITIDIERO, Daniel. Cortes superiores como cortes supremas: do controle à interpretação da jurisprudência ao precedente. 2. Ed. São Paulo: Revista dos Tribunais, 2014; MITIDIERO, Daniel. Precedentes: da persuasão à vinculação. São Paulo: Revista dos Tribunais, 2016; MARINONI, Luiz Guilherme. A ética dos precedentes: justificativa do novo CPC. 2. Ed. São Paulo: Revista dos Tribunais, 2016.

${ }^{29}$ Para uma crítica específica à perspectiva das Cortes Supremas, conferir: ROSSI, Júlio César. A interpretação do direito é monopólio das Cortes Supremas? Empório do Direito. São Paulo. 04 mai. 2020. Disponível em: https://bit.ly/303echV; ROSSI, Júlio César; MUNDIM, Luís Gustavo Reis. Reclamação e cortes supremas: contrapontos às teses do professor Daniel Mitidiero. Revista Brasileira de Direito Processual - RBDPro, Belo Horizonte, ano 29, n. 113, p. 199-217, jan./mar. 2021; MUNDIM, Luís Gustavo Reis. O antagonismo entre a ética dos precedentes e o Estado Democrático de Direito. Revista eletrônica de direito processual - REDP. Rio de Janeiro, ano 13, v.20, n. 01, jan./abr. 2019, p. 315-340. Disponível em: https://bit.ly/3g6QaYZ; MUNDIM, Luís Gustavo Reis. Op. cit., 2018 e MUNDIM, Luís Gustavo Reis; VARELA, Alexandre de Oliveira. Cortes supremas e a herança bülowiana na jurisprudencialização do direito. Revista eletrônica de direito processual - REDP. Rio de Janeiro, ano 13, v.20, n. 03, set./dez. 2019, p. 293-322. Disponível em: https://bit.ly/39usUBR.

30 "Precedentes (ou provimentos vinculantes) não são feitos para balizar decisões no futuro; precedente não é uma norma geral, ele é concreto; precedentes são produtos, não produtores. Enfim, qualquer provimento vinculante - com exceção da decisão que nulifica uma lei - é aplicado sempre contingencialmente”. STRECK, Lenio Luiz. A (nova) reclamação no CPC/2015. Revista Brasileira de Direito Processual - RBDPro, Belo Horizonte, ano 24, n. 93, p. 129-147, jan./mar.2016, p.141-142.

Em mesma perspectiva, consultar: ROSSI, Júlio César. Precedente à brasileira: a jurisprudência vinculante no CPC e no novo CPC. São Paulo: Atlas, 2015.

${ }^{31}$ Sobre uma crítica ao modelo de busca por eficiência meramente quantitativa da atividade jurisdicional, conferir: FREITAS, Helena Patrícia. Eficiência da jurisdição: necessidade de sua (des)construção para efetivação do modelo constitucional de processo. Belo Horizonte: D’Plácido, 2019. 
Rio de Janeiro. Ano 15. Volume 22. Número 3. Setembro a Dezembro de 2021

Periódico Quadrimestral da Pós-Graduação Stricto Sensu em Direito Processual da UERJ

Patrono: José Carlos Barbosa Moreira (in mem.). ISSN 1982-7636. pp. 523-540 www.redp.uerj.br

formado pelo referido tribunal. Essa paradoxal ${ }^{32}$ elevação de Tribunais Superiores ao status de Cortes Supremas acaba por negar a normatividade da Constituição e do próprio CPC, já que apenas mantém uma excepcionalidade cotidiana ${ }^{33}$ imposta por julgadores portadores de saberes transcendentais infalíveis.

O que se tem, então, é uma total ausência de controle das decisões advindas do STJ, que trata a norma jurídica como criação jurisprudencial, conforme crítica Rosemiro Pereira Leal:

Se essa interpretação é concebida como dogmática (doutrina) pela convicção de que a norma jurídica é uma criação da interpretação da autoridade jurisdicional ante a escrita legal, fica explícito que o disposto na escritura dos arts. 926 e 927 não traria qualquer ganho democrático (sentido neoinstitucionalista) para o direito brasileiro, porque o forte efeito vinculante dos precedentes (strong biding-force) seria uma força (violência) nascida da atuação intelectiva da autoridade

com afastamento do medium linguístico do devido processo (sentido neoinstitucionalista).

De consequência, nessas cogitações, a chamada novidade jurídica do instituto do precedente apresentar-se-ia inócua à obtenção de um salto democrático pela submissão das disposições do CPC/2015 às normas fundamentais da $\mathrm{CF} / 88$ (art. $1^{\circ}$ do CPC/2015). ${ }^{34}$

Percebe, então, é que a impossibilidade de cabimento da Reclamação, da forma decidida pelo STJ, não traz qualquer racionalidade ao pseudosistema de precedentes, já que, pelo contrário, jurisprudencializa o direito e cria “uma irracionalidade pela total ausência de crítica, mesmo que essas decisões se reportem a normas legais, haja vista que apenas o exercício de uma fiscalidade jurídica irrestrita e processualizada da validade normativa é legitimadora do encaminhamento decisório". 35

Conclui-se, então, que o truculento entendimento do STJ é um réquiem à processualidade democrática, à legalidade e à constitucionalidade.

\section{V - CONSIDERAÇÕES FINAIS}

\footnotetext{
${ }^{32}$ SOARES, Carlos Henrique. Paradoxos dos precedentes judiciais. Revista Brasileira de Direito Processual - RBDPro, Belo Horizonte, ano 25, n. 100, p. 55-83, out./dez. 2017.

${ }^{33}$ LEAL, André Cordeiro; THIBAU, Vinicius Lott. A dogmática processual e a exceção cotidiana. Revista Brasileira de Direito Processual - RBDPro, Belo Horizonte, ano 23, n.92, p. 13- 29, out./dez.2015.

${ }^{34}$ LEAL, Rosemiro Pereira. A questão dos precedentes e o devido processo. Revista Brasileira de Direito Processual - RBDPro, Belo Horizonte, ano 25, n. 98, p. 295 - 313, abr./jun.2017, p. 306.

${ }^{35}$ FARIA, Gustavo de Castro. Jurisprudencialização do direito: reflexões no contexto da processualidade democrática. Belo Horizonte: Arraes, 2012, p.105.
} 
Somos críticos desse sistema no interior do qual confundem-se precedentes com provimentos (=pronunciamentos) vinculantes. ${ }^{36}$ Esses últimos, por aqui, nascem, desenvolvem-se e produzem efeitos "no" e a partir "do" âmbito das "Cortes Supremas", irradiando-se para todo o ordenamento processual; mas, se ele está aí posto, que sejamos minimamente coerentes com o "pacote completo" (=combo).

Nesse passo, ser coerente com o modelo significa, em última análise, reconhecer o cabimento da reclamação como genuína solução processual apta a ensejar: (i) a adequação do ato impugnado ao parâmetro vinculante ou (ii) proceder a revisão deste último composto em sede de julgamento de recurso extraordinário com repercussão geral reconhecida ou proferido em julgamento de recursos extraordinário ou especial repetitivos.

$\mathrm{O}$ futuro da reclamação à vista do "estado da arte" aproximar-se-ia, metaforicamente, tal qual o destino do Gato de Schrödinger ${ }^{37}$, ou seja, não saberemos, ao certo, o que está no interior da caixa enquanto não for aberta pelo protagonista que suscita o colapso (=paradoxo) o qual, ao fim e ao cabo, é o responsável pela vida ou pela morte do Felis catus.

\section{REFERÊNCIAS}

ABBOUD, Georges. Processo constitucional brasileiro. 3. ed. São Paulo: RT, 2019.

; NERY, Nelson. Recursos para os tribunais superiores e a lei 13.256/2016. Revista de Processo. vol. 257/2016. São Paulo: RT, jul. 2016.

ARAÚJO, José Henrique Mouta. A reclamação constitucional e os precedentes vinculantes: o controle da hierarquização interpretativa no âmbito local. Revista de Processo. n. 252. São Paulo: RT, fev. 2016.

ASSIS, Araken de. Manual dos recursos. 8. ed., São Paulo: RT, 2016.

\footnotetext{
${ }^{36}$ No mesmo sentido: STRECK, Lenio Luiz. Precedentes judiciais e hermenêutica: o sentido da vinculação no CPC/2015. Salvador: JusPodivm, 2018.

${ }^{37} \mathrm{O}$ "Gato de Schrödinger" é uma experiência mental, verdadeiro paradoxo, idealizado pelo físico austríaco Erwin Schrödinger (1.935). Grosso modo: há um Gato cerrado em uma caixa na companhia de uma fonte de decaimento radioativo, um contador Geiger e um frasco de vidro selado com veneno. Se o contador Geiger detectar o decaimento radioativo de um único átomo, ele quebra o frasco, matando o felino. Contudo, não é possível observar o interior do invólucro; logo, ao menos enquanto o experimento permanecer lacrado $(=\operatorname{sem}$ acesso pelo observador), é impossível saber se o bichano está vivo ou morto. Por isso, considera-se que o animal está, ao mesmo tempo, vivo-morto.
} 
BORGES, Fernanda Gomes e Souza. Demérito ao STJ: a relevância da reclamação diante do fenômeno do "manicômio jurisprudencial". Empório do Direito. São Paulo. jun. 2020. Disponível em: https://bit.ly/3hGh4Ye.

. Os novos contornos da reclamação constitucional no Código de Processo Civil de 2015. Revista Brasileira de Direito Processual - RBDPro, Belo Horizonte, ano 26, n. 102, p. 235-256, abr./jun. 2018.

DIMOULIS, Dimitri; LUNARDI, Soraya. Curso de processo constitucional: controle de constitucionalidade e remédios constitucionais. 7. ed. São Paulo: RT, 2020.

FARIA, Gustavo de Castro. Jurisprudencialização do direito: reflexões no contexto da processualidade democrática. Belo Horizonte: Arraes, 2012.

FREITAS, Helena Patrícia. Eficiência da jurisdição: necessidade de sua (des)construção para efetivação do modelo constitucional de processo. Belo Horizonte: D’Plácido, 2019.

GRESTA, Roberta Maia. Introdução aos fundamentos da processualidade democrática. Coleção estudos da Escola Mineira de Processo. Rio de Janeiro: Lumen Juris, 2014. v. 01.

LEAL, André Cordeiro. THIBAU, Vinicius Lott. A dogmática processual e a exceção cotidiana. Revista Brasileira de Direito Processual - RBDPro, Belo Horizonte, ano 23, n.92, p. 13- 29, out./dez.2015.

LEAL, Rosemiro Pereira. A questão dos precedentes e o devido processo. Revista Brasileira de Direito Processual - RBDPro. Belo Horizonte, ano 25, n. 98, p. 295-313, abr./jun.2017.

MARINONI, Luiz Guilherme. A ética dos precedentes: justificativa do novo CPC. 2. ed. São Paulo: Revista dos Tribunais, 2016.

MEDINA, José Miguel Garcia. Curso de direito processual civil moderno. 3. ed. São Paulo: RT, 2017.

MITIDIERO, Daniel. Cortes superiores como cortes supremas: do controle à interpretação da jurisprudência ao precedente. 2. ed. São Paulo: Revista dos Tribunais, 2014.

. Precedentes: da persuasão à vinculação. São Paulo: Revista dos Tribunais, 2016.

MUNDIM, Luís Gustavo Reis. O antagonismo entre a ética dos precedentes e o Estado 
Democrático de Direito. Revista eletrônica de direito processual - REDP. Rio de Janeiro, ano 13, v.20, n. 01, jan./abr. 2019, p. 315-340. Disponível em: https://bit.ly/3g6QaYZ.

. Precedentes: da vinculação à democratização. Belo Horizonte: D’Plácido, 2018 .

; VARELA, Alexandre de Oliveira. Cortes supremas e a herança bülowiana na jurisprudencialização do direito. Revista eletrônica de direito processual - REDP. Rio de Janeiro, ano 13, v.20, n. 03, set./dez. 2019, p. 293-322. Disponível em: https://bit.ly/39usUBR.

NUNES, Dierle; FREITAS, Marina Carvalho. O STJ e a necessidade de meios para a superação dos precedentes. Consultor jurídico. São Paulo. nov. 2017. Disponível em: https://bit.ly/3jDBp29.

ROSSI, Júlio César. A interpretação do direito é monopólio das Cortes Supremas?. Empório do Direito. São Paulo. mai. 2020. Disponível em: https://bit.ly/303echV.

. Precedente à brasileira: a jurisprudência vinculante no CPC e no novo CPC. São Paulo: Atlas, 2015.

Aspectos processuais da reclamação constitucional. Revista Dialética de Direito Processual, n. 19, p. 49-60, out. 2004.

ROSSI, Júlio César; MUNDIM, Luís Gustavo Reis. Reclamação e cortes supremas: contrapontos às teses do professor Daniel Mitidiero. Revista Brasileira de Direito Processual - RBDPro, Belo Horizonte, ano 29, n. 113, p. 199-217, jan./mar. 2021

SOARES, Carlos Henrique. Paradoxos dos precedentes judiciais. Revista Brasileira de Direito Processual - RBDPro, Belo Horizonte, ano 25, n. 100, p. 55-83, out./dez. 2017.

STRECK, Lenio Luiz. A (nova) reclamação no CPC/2015. Revista Brasileira de Direito Processual-RBDPro, Belo Horizonte, ano 24, n. 93, p. 129-147, jan./mar.2016

STRECK, Lenio Luiz. Precedentes judiciais e hermenêutica: o sentido da vinculação no CPC/2015. Salvador: JusPodivm, 2018.

TORRANO, Bruno. Pragmatismo no direito e a urgência de um pós-pós-positivismo no Brasil. Rio de Janeiro: Lumen juris, 2018. 